\title{
LA OPINIÓN PÚBLICA A FINALES DEL SIGLO XIX EN ESPAÑA
}

\section{PUBLIC OPINION IN THE LATE NINETEENTH CENTURY IN SPAIN}

\section{AUTOR}

\section{Cándido Monzón Arribas}

Profesor en la Facultad de Ciencias de la Información de Universidad Complutense de Madrid (España) monzon43@ccinf.ucm.es

\section{RESUMEN}

Gracias a la aparición de la democracia y del sufragio censitario -que después evolucionó al universal masculino-, es posible la aparición de la opinión pública. La opinión pública resulta ser clave para llevar a cabo unas decisiones políticas que, principalmente, sirven para ofrecerle un papel protagonista al pueblo. De este modo, el pueblo elegirá a su representante político y éste, a su vez, trabajará para ofrecer al pueblo lo que éste necesita.

\section{PALABRAS CLAVE}

Sufragio - Opinión pública - Educación - Libertad de expresión - Democracia

\section{ABSTRACT}

With the emergence of democracy and suffrage, this later evolved censitary the universal masculine, it is possible the emergence of public opinion. Public opinion turns out to be key to carrying out political decisions that mainly serve to give the 
people a leading role. Thus, the people elect a political representative and this, in turn, will work to give the people what they need.

\section{KEY WORDS}

Suffrage - Public Opinion - Education - Freedom of expression - Democracy

\section{ÍNDICE}

1. Qué se dice sobre la opinión pública en España a finales del siglo XIX.

2. La opinión pública en las instituciones.

3. Autores que escriben sobre opinión pública.

4. Cómo funciona la opinión pública.

5. Educación y analfabetismo.

6. Libertad de expresión.

7. Participación.

8. Bibliografía. 


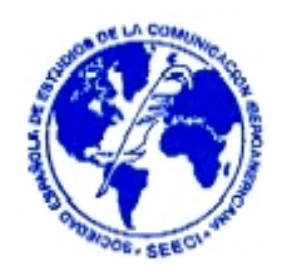

Apoyándonos en lo que años más tarde dijera Ortega y Gasset en numerosos escritos (De Re Política, Vieja y nueva política, Cunegunda o la opinión pública española, La rebelión de las masas, El hombre y la gente, entre otros) podemos afirmar que apenas si era perceptible su existencia y escasa su incidencia en la sociedad, sobre todo, en el poder. Cuantas veces ésta hacía su aparición en público (o a través del sufragio, por ejemplo), al igual que ocurriera con al gentil Cunegunda de Voltaire, ésta salía de alguna manera violada o maltratada. Y, aunque la libertad de prensa (recogida en la Ley de 26/7/1883) fue un elemento a favor que pudo permitir la aparición de una opinión pública, crítica y eficaz, las condiciones políticas, sociales y culturales que arrastraba la sociedad españolas desde principios de siglo (XIX) hacían prácticamente imposible que la opinión pública consiguiera el peso que alcanzó en otros países democráticos del mundo occidental.

La debilidad que la opinión pública tenía en la vida real -como fenómeno social de masas- no quita que hubiera una preocupación moderada en ámbitos académicos e institucionales por subrayar la importancia de su existencia y la necesidad de su presencia en los ámbitos públicos para hacer posible el funcionamiento de las instituciones democráticas. En este sentido se puede afirmar que seguíamos un camino paralelo al del resto de los países de Europa, con la salvedad de que caminábamos un poco por detrás y con un tratamiento teórico de menor profundidad.

El objetivo de nuestra exposición, por tanto, se va a centrar en dos puntos. En primer lugar, vamos a describir la preocupación académica y teórica que algunos estudiosos del tema dieron a la opinión pública en los años que rodean el final del siglo XIX y, en segundo lugar, aportaremos algunos datos que permitan entender las dificultades que encontraba la opinión pública, como fenómeno social, para su existencia y desarrollo en la sociedad. 


\section{Qué se dice sobre la opinión pública en España a finales del siglo XIX.}

Se suele aceptar que la opinión pública entra en la historia de la mano de J. J. Rousseau y de los Fisiócratas (segunda mitad del siglo XVIII), algunas de cuyas ideas se introducen en España a finales de siglo a través de instituciones, como la Sociedad Económica de Amigos del País o la Sociedad Económica Matritense y de autores como F. de Cabarrus (que apela al "Tribunal de la Opinión Pública", como anteriormente lo hiciera Necker, en Francia) o Gaspar M. de Jovellanos, el primer autor que escribe sobre esta materia en nuestro país (Reflexiones sobre la opinión pública, escrita entre 1790 y 1797) $)^{1}$.

Como precedentes de la época que estamos analizando -finales del siglo XIXtambién que hacer referencia a todos los acontecimientos que se suceden en torno a la Guerra de la Independencia (libertad de prensa, elecciones, Constitución de 1812, nacimiento de la primera cultura del pueblo); la importancia que dan los doctrinarios a la opinión pública dentro del juego y equilibrio de poderes, el reconocimiento del sufragio, primero censitario y, en 1869, universal masculino; la aparición de ateneos, liceos, casinos, cafés, etc. donde se hace posible, aunque seas con públicos reducidos, la formación de una auténtica opinión pública y, finalmente, las diferentes leyes relacionadas con la libertad de expresión, en unos casos con espíritu conservador y, en otros, con talante progresista.

Ampliando por arriba y por abajo el final del siglo XIX, el tratamiento que se hace de la opinión pública girará en torno al krausismo y el positivismo, la Institución Libre de

\footnotetext{
${ }^{1}$ Sobre la Historia de la Opinión Pública en España se pueden consultar los trabajos del profesor J. I. Rospir, especialmente: "La Opinión pública en España", en A. Muñoz Alonso, C. Monzón, J. I. Rospir y J. L. Dader, Opinión Pública y comunicación política, Eudema, Madrid, 1990.
} 
Enseñanza y ciertas actividades relacionadas con el mundo universitario. $Y$, aunque sean las ciencias jurídico-políticas las que lleven el peso principal en el desarrollo de esta materia, no se descartan -y se reclamarán en su momento- nuevas perspectivas, como las que aportan la sociología y la psicología.

Los temas y capítulos sobre los que gira el planteamiento teórico de la opinión pública, se refieren, principalmente a:

a) Naturaleza, concepto y definición.

b) Factores que intervienen en su formación;

c) Proceso y organización de la opinión pública;

d) Ámbitos de actuación, expresión y manifestación;

e) La opinión pública como fuera política en un régimen de opinión;

f) También extiende su análisis a conceptos relacionados con la opinión pública, como los usos, costumbres, ideas, creencias, conciencia social, espíritu público o colectivo.

g) Y, a algunos factores en que participan en su formación y expresión, como el sufragio, partidos políticos, asambleas, parlamento, publicidad y prensa. 


\section{La opinión pública en las instituciones}

El desarrollo de la opinión pública, decíamos antes, va unido a actividades de discusión y publicidad en ateneos, academias e instituciones, especialmente en la Institución Libre de Enseñanza. En todos ellos -y algunos más como los cafés- los públicos allí reunidos hacían opinión pública, y de vez en cuando, se daban conferencias o se hablaba sobre el tema en cuestión. En el período que estamos analizando, por ejemplo, Manuel Conrrote, en 1888, lee la memoria en la Real Academia de Legislación y Jurisprudencia, con el título: "Influencia que la Opinión Pública puede y debe ejercer sobre el poder judicial"; el Ateneo de Madrid, en abrir de 1884, organiza un ciclo de conferencias sobre la opinión pública, donde hablan sobre el tema F. de Silvela: "Opinión Pública, examinada bajo sus diferentes aspectos y modos de formarse" y Canalejas: "La opinión pública y el Parlamento".

Será la Institución Libre de Enseñanza, sin embargo, la que ofrezca las mejores oportunidades para el estudio y publicidad de la opinión pública, como puede constatarse en su Boletín donde se recoge la traducción y publicación de algunos autores alemanes, se imprimen artículos españoles sobre la opinión pública y se publica parte de la primera tesis doctoral en esta disciplina.

\section{Autores que escriben sobre opinión pública}

En cuanto a los autores, Arcadio Roda Rivas, en 1870, escribe su Ensayo sobre la opinión pública, donde, desde un planteamiento teórico y general, se pregunta sobre el concepto de esta disciplina, las relaciones que mantiene la opinión pública con la vida política y las diferentes formas que tiene de manifestarse. Unos años más tarde, Gumersindo de Azcárate publicará en 1885 el Régimen Parlamentario en la Práctica. En esta obra defiende la necesidad de una opinión pública como camino para llegar a un auténtico régimen parlamentario y democrático. Reclama la presencia en la vida política del pueblo (la "masa neutra" de los conservadores), y afirma que si éste no 
participa en el proceso, ello es debido a la corrupción einmoralidad de los políticos o al falseamiento que se hace del régimen parlamentario. En la formación, actuación y expresión de la opinión pública destaca el papel de los partidos y, sobre todo, de la prensa política que, como "cuarto poder" desarrolla las funciones de orientación, dirección y expresión.

La primera (posiblemente) tesis doctoral sobre opinión pública la realiza Alberto López Selva y de su existencia tenemos conocimiento a través de las referencias de A. Posada y G. de Azcárate y de la publicación que se hace de algunos capítulos en el Boletín de la Institución Libre de Enseñanza (en los mese de enero a abril de 1890), bajo el título Sobre la opinión pública. Como sostiene J. I. Rospir, "el trabajo de López Selva es importante por el programa, por la organización que establece y por el estudio e investigación que realiza" (Rospir, 1990, 117). Sus capítulos principales hacen referencia al espíritu público, el concepto de opinión, proceso y elementos que intervienen en su formación, esferas de acción y manifestaciones de la opinión pública.

Luis Garcia de los Ríos, siguiendo los pasos de López Selva, publica su tesis doctoral en 1910 con el escueto título La Opinión Pública. En ella se habla principalmente de la costumbre y la opinión pública, los órganos que expresan y dirigen la opinión pública y si la opinión pública puede ser fuente directa de derecha. Aunque la tesis forma parte de los primeros escritos del siglo XX sobre la opinión pública, la citamos aquí por la relación que tiene con la tesis anterior y por formar parte de una corriente universitaria que pervivirá hasta la Segunda República (Adolfo Posada, M. Salas y Ferré, A. Roda Rivas, A. Casses Casan y J. Ortega y Gasset).

Adolfo Posada forma parte de aquellos autores que, partiendo de una formación jurídica-política profunda, reclama nuevas perspectivas para el estudio de la opinión pública. Su nivel científico-académico y amplitud de miras queda manifiesto en la bibliografía sobre opinión pública (jurídico.-política, sociológica y psicológica) que 
incluye en las últimas ediciones (1928 y 1935) de su Curso de Derecho Político (1893). Además del Curso, deben tenerse en cuenta los artículos publicados en el Boletín de la Institución Libre de Enseñanza, en 1909: Sobre la Opinión Pública y Naturaleza de la opinión pública. En el Curso, siguiendo a Bryce, distingue los gobiernos de opinión (por su representatividad) de aquellos que no lo son, desconfía de las estadísticas electorales españolas, recoge las ideas de publicidad de los alemanes Röder y Schaffle, explica las formas de expresarse a través del sufragio, los partidos, el Parlamento, las asambleas, etc., y siguiendo a Azcárate, destaca el papel que juega la prensa en su formación y expresión.

En los artículos que publica en el Boletín manifiesta su preocupación por la creación de una teoría de la opinión pública, defendiendo (como Holtzenclorff) su carácter interdisciplinas. Bajo la influencia de Cooley identifica opinión pública con organización, hablando de ella como un estado de conciencia colectiva o expresión del espíritu social que da vida a la sociedad. Todas estas ideas quedan recogidas y ampliadas en las últimas ediciones de El Curso.

\section{Cómo funciona la opinión pública}

La primera y gran teoría sobre la opinión pública viene de los liberales y en sus orígenes (los liberales clásicos) sostenían que para hacer posible la existencia de un opinión pública real, previamente debían cumplirse una serie de requisitos, entre los que podemos destacar tres: a) educación (conocimiento, cultura), libertades $y$, en nuestro caso, b) libertad de expresión (de imprenta, de opinión) y c) participación (en las elecciones, en asociaciones intermedias, etc.). El estado de estos tres requisitos en España a finales del siglo XIX nos podrá explicar en gran parte el funcionamiento real de la opinión pública y la idea negativa que de ella tenían algunos autores, como hemos mencionado anteriormente. 


\section{Educación y analfabetismo}

Hay un primer dato relacionado con la educación que ha condicionado fuertemente cualquier manifestación de tipo cultural $y$, en el tema que estamos tratando, de cultura política y opinión pública: la alta tasa de analfabetismo en España durante el siglo XIX y gran parte del XX.

La Constitución de 1812 había dispuesto de manera indirecta la universalidad de la primera enseñanza (a. 366) y, de forma explícita, la uniformidad de la misma (a. 368). El Reglamento, posteriormente, completará el artículo anterior al disponer que la enseñanza costeada por el Estado deberá hacerse pública y gratuita. La Ley Moyano, a mediados de siglo (9/9/1857), establecerá el criterio de una escuela primaria por cada 500 habitantes, pero ésta y otras leyes tendrán una eficacia limitada, ya que el analfabetismo será una de las características dominantes de la población española a pesar que las estadísticas mostraban una gran abundancia de escuelas. Por otro lado, una parte importante de la educación, especialmente la básica y la media, estaba en manos de la Iglesia (Artola, 1973: 278-280).

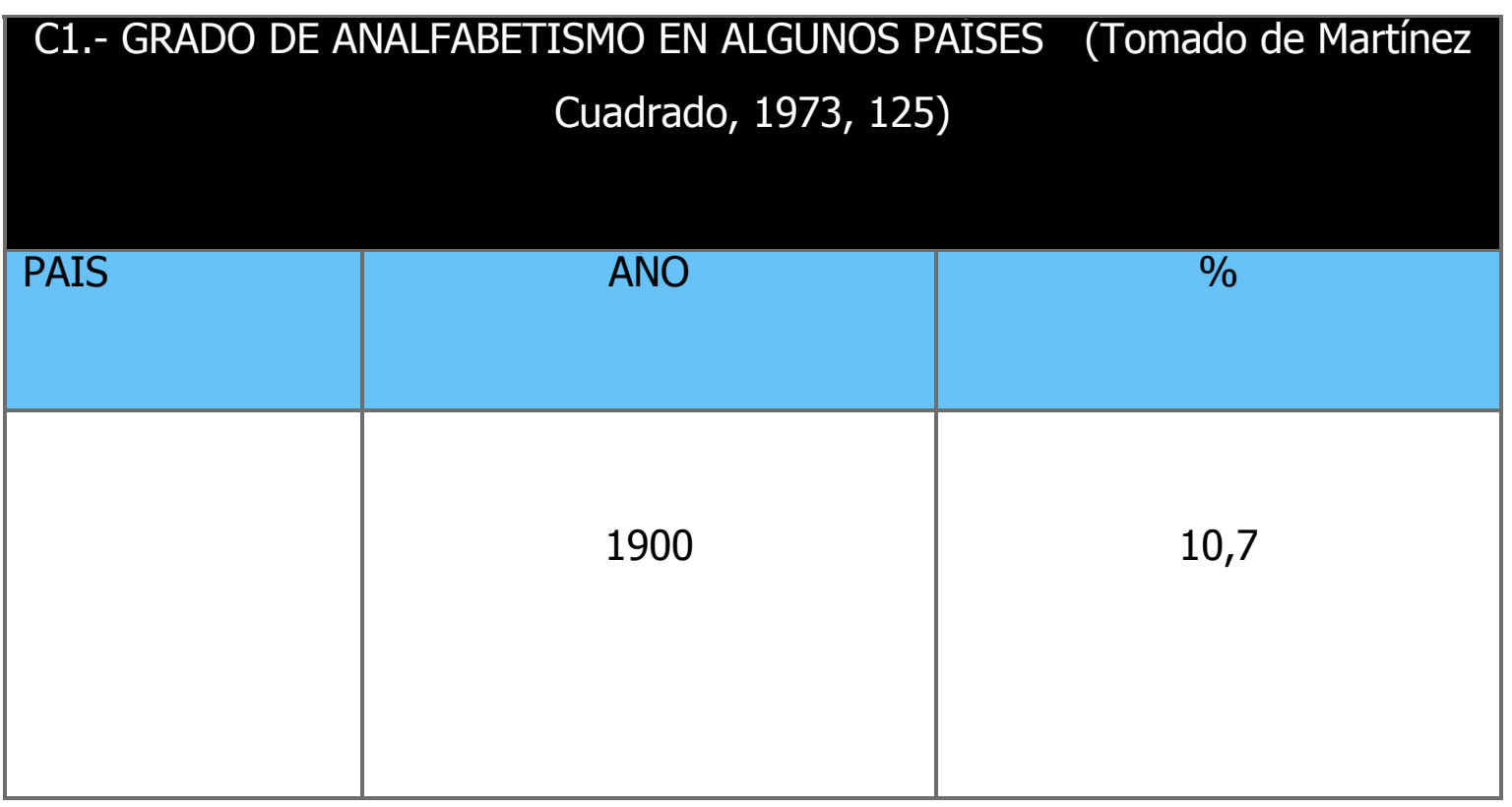




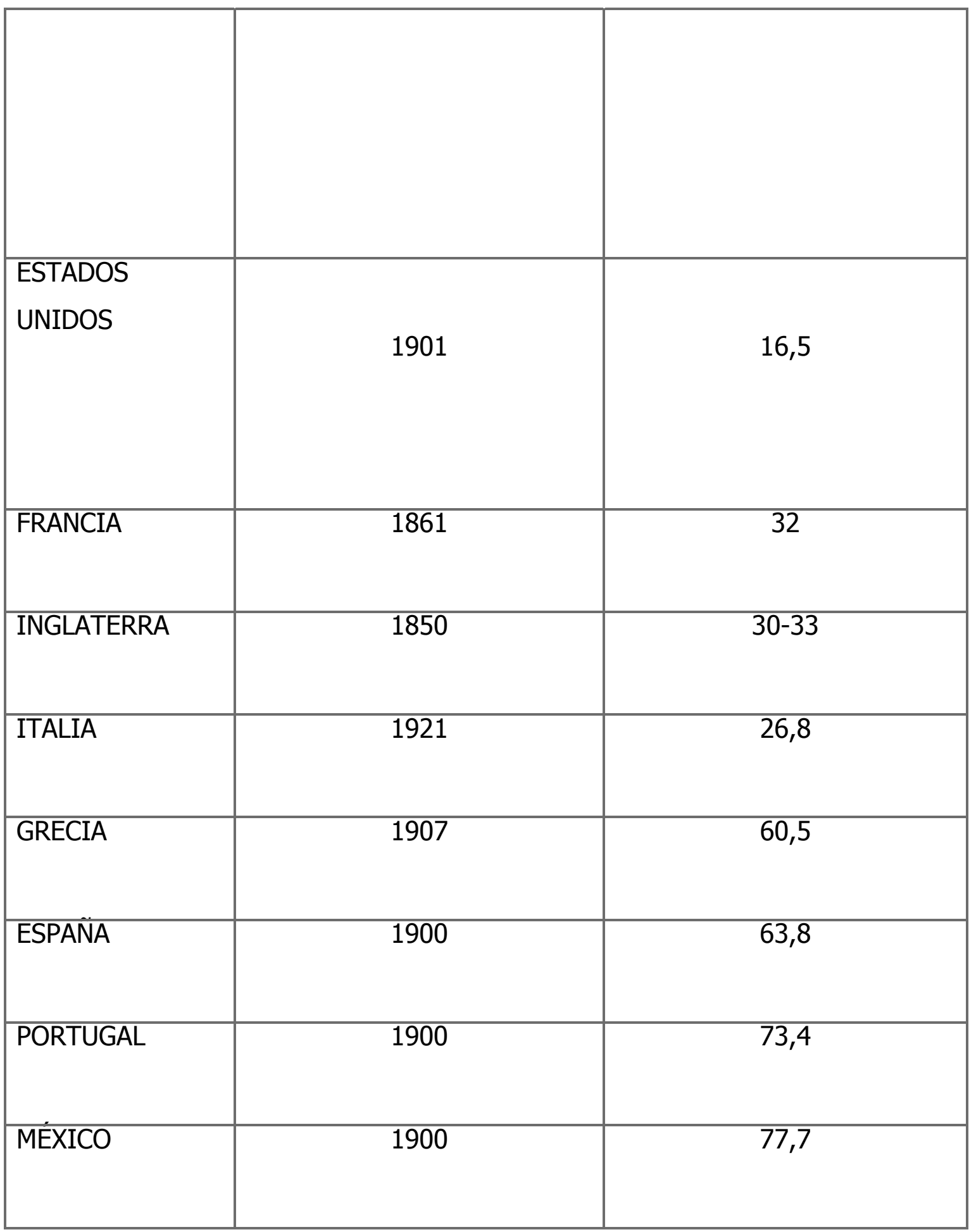

Para entender lo que estamos diciendo, nada mejor que comparar el grado de analfabetismo reinante en España con el de aquellos países próximos en distancia y cultura. Como puede verse en el cuadro 1, nos encontramos a una distancia 
considerable de Francia, Inglaterra o Estados Unidos -países de larga tradición democrática donde ha dominado el régimen de opinión- y muy próximos a países como Portugal, Grecia o México -países apegados a régimenes autocráticos y con una cultura dominante de súbdito (Almond y Verba, 1970).

Centrándonos en España (cuadro 2), más de la mitad de la población sigue siendo analfabeta hasta el año 1920, porcentaje que no será reducido notablemente hasta finales de los años cuarenta. El analfabetismo se hace más patente entre las mujeres que en los hombres, con un porcentaje medio superior al 20 por 100.

\begin{tabular}{|c|c|c|c|}
\hline \multicolumn{4}{|c|}{ Cuadrado, 1973, 124) } \\
\hline AÑO & $\%$ TOTAL & $\%$ Hombres & $\%$ Mujeres \\
\hline 1860 & 80 & --- & --- \\
\hline 1877 & 72 & 62 & 81 \\
\hline 1887 & 71,6 & 61,5 & 81,2 \\
\hline 1900 & 63,8 & 55,8 & 71,5 \\
\hline 1910 & 59,4 & 52,6 & 65,8 \\
\hline 1920 & 52,3 & 46,4 & 57,8 \\
\hline
\end{tabular}




\begin{tabular}{|c|c|c|c|}
\hline 1930 & 44,4 & 38,7 & 58,2 \\
\hline 1940 & 33,7 & 29,7 & 37,8 \\
& & & \\
\hline 1979 & 8,2 & 4,7 & 11,5 \\
& & & \\
\hline
\end{tabular}

\section{Libertad de expresión.}

Si hay un factor altamente relacionado con la opinión pública (libertad de opinión) ése es la libertad de expresión y, ésta, a lo largo del siglo y medio, se ha canalizado principalmente a través de los medios de comunicación. Se necesita, por un lado, un marco legal que la ampare (libertad de prensa e imprenta) y, por otro, la creación de medios adecuados para informar y dar publicidad a las opiniones.

En España, la llegada de la Restauración impondrá cierto orden en el sector de los medios, aunque en alguno de los decretos que aparecen renacerá la vieja idea de la censura y el control. En el Decreto de 29/1/1875, por ejemplo, se recogen ciertas sanciones a la prensa; en la Constitución de 30/6/1876, se reconoce, sin embargo, a libertad de expresión; en la Ley de 7/1/1879, vuelven de nuevo las limitaciones a la prensa y en la Ley de $26 / 7 / 1883$, se liberará definitivamente a la misma de la censura. De alguna manera se están creando las condiciones para el periodismo del siglo XX, aunque en España, la prensa de masas propiamente dicha no aparecerá hasta la Segunda República.

La prensa de finales de siglo, aunque sigue siendo una prensa de opinión y de partido, se verá reforzada por fenómenos como el de la propaganda (con sus grupos de respaldo) durante el primer tercio del siglo $\mathrm{XX}$, la entrada en el mundo 
periodístico de destacados intelectuales (sobre todo, a partir del 98) con todo lo que esto lleva consigo de liderazgo político y de opinión y la conversión de la empres periodística en empresa de negocio (aparecen las agencias de noticias y la publicidad) (Timoteo, 1989, 11-26). Sin embargo, aunque la prensa tiene ya su libertad, la información apenas si llega a la población, especialmente la rural: las tasas de analfabetismo superar el 60 por 100, son altos también los índices de pobreza y la cultura política del país todavía se encuentra anclada en esquemas medievales.

Libertad de prensa, sí, pero ciertas condiciones socio-económicas, políticas y culturales hacen prácticamente imposible el surgimiento de un régimen de opinión.

\section{Participación.}

Cuando hablamos de participación política nos estamos refiriendo a la participación de la población en actos electorales, como el sufragio. El sistema electoral en España empieza a funcionar en 1810, con el sufragio universal indirecto para elecciones de Juntas y, hasta finales del siglo XIX, pasará por el sufragio indirecto censitario (1834), universal indirecto (1836), censitario (1837), universal masculino (1869), censitario (1879) y universal masculino (1891). Este sistema pervivirá, siempre que haya elecciones, hasta 1933, cuando la Constitución promulgada este año implanta el sufragio universal.

Los últimos años del siglo XIX y los primeros del XX se encuentran dentro de una etapa liberal que, teóricamente, tuvo grandes oportunidades para construir una cultura política de participación. El reinado de Alfonso XII (1875-1885), la Regencia de María Cristina (1885-1902) y posteriormente el reinado de Alfonso XIII no crearán los marcos políticos adecuados para que el pueblo crezca en información, cultural, participación y responsabilidad cívica. Además, en los últimos años del siglo, el ejército pierde el talante liberal que le había caracterizado durante décadas, ciertos 
usos políticos como el control electoral, el caciquismo, el turismo, el bipartidismo y la aplicación de leyes como el artículo 29 de la Ley Electoral de 1907, provocarán la abstención electoral en una parte importante de la población y la incomunicación política entre el poder y los ciudadanos. Las secuelas de este período han estado presentes a lo largo de todo el siglo y aún, en la actualidad, se pueden encontrar algunas claves de la abstención política en el período que estamos analizando.

Entre 1891 y 1903, los datos de la abstención electoral quedan como sigue:

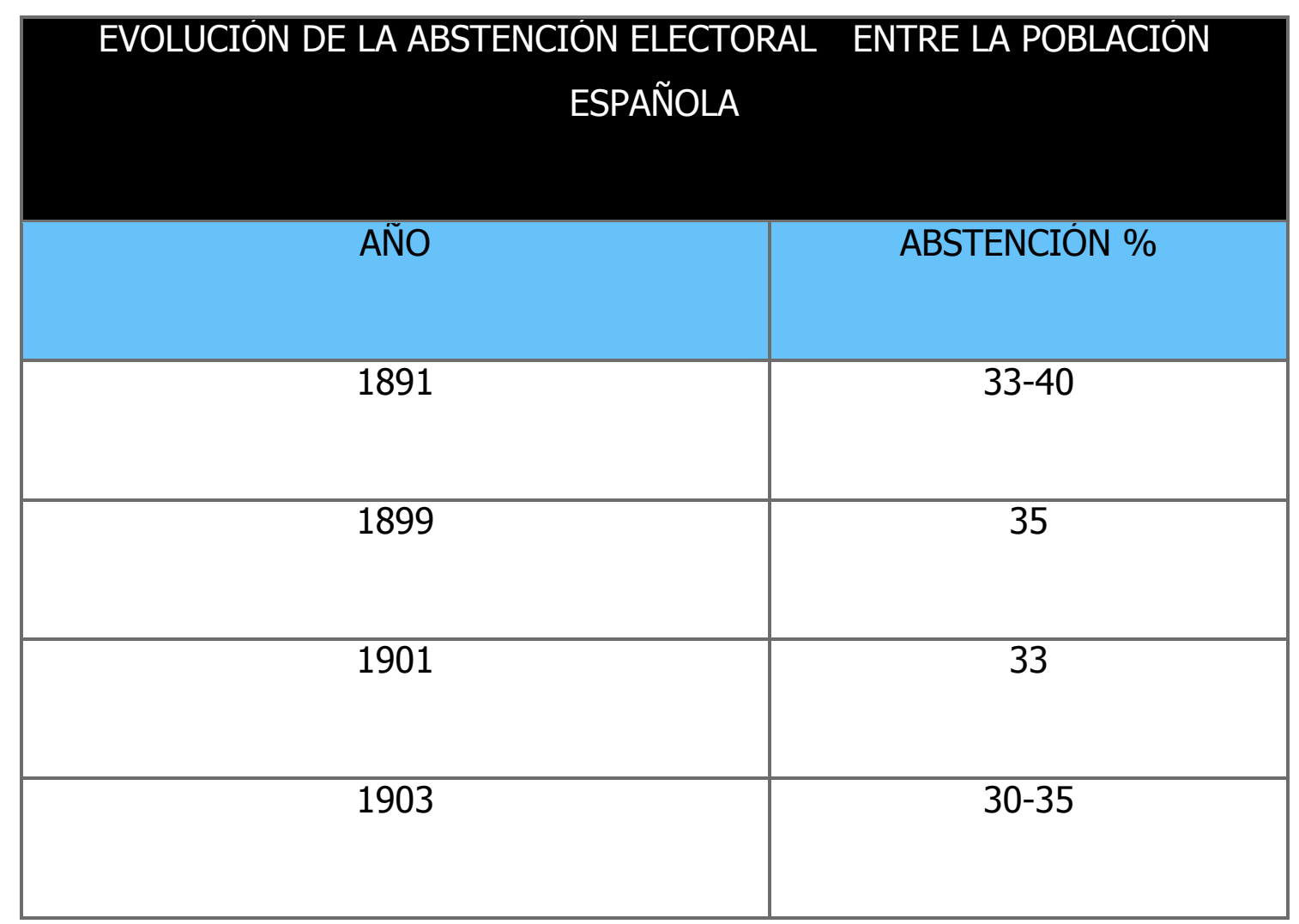

Como conclusión a estas breves líneas sobre la opinión pública en la España de finales del siglo XIX diremos que, aunque se siguen los pasos de todo lo que acontece y se escribe en Europa y Norteamérica, hay cierta preocupación intelectual e institucional por los temas de opinión pública y, en estos ámbitos, la preocupación aumenta de tono cuando se refieren a la existencia real de una opinión y conciencia 
pública general.

Como fenómeno popular, apenas si tiene existencia, políticamente se encuentra secuestrada y cuando funciona, ésta tiene las características de académica, mediática, elitista, urbana, fuertemente ideologizada $y$, en las zonas industriales, obrerista. Aunque formalmente durante el siglo XIX y principios del XX predominan los regímenes democráticos, el régimen de opinión como expresión de amplias capas de la sociedad que dialogan, discuten y controlan todo aquello que es de interés público, incluido el poder, apenas si tiene existencia. La imagen de Cunegunda, aplicada por Ortega a la opinión pública, expresa perfectamente la situación de finales y principio de siglo.

\section{Bibliografía}

ABELLÁN, J. L.(1981): Historia crítica del pensamiento español. Espasa Calpe. Madrid.

ALMOND, G. y VERBA, S. (1970): La cultura cívica. Suramérica. Madrid.

ARTOLA, M. (1973): La burguesía revolucionaria. Alianza. Madrid

FERNÁNDEZ AREAL, M. (1971): La libertad de prensa en España . Madrid.

MARAVALL, J. A. (1975): Estudios de historia del pensamiento español . Cultura Hispánica. Madrid.

MARTÍNEZ CUADRADO, M. (1973): La burguesía conservadora . Alianza. Madrid.

MONZÓN, C. (1991): Opinión pública, comunicación y política. Tecnos. Madrid. 
MUÑOZ ALONSO, A., MONZON, C., ROSPIR, J. I. y DADER, J. L.v(1990): Opinión Pública y comunicación política . Eudema. Madrid.

POSADA, A. (1883, 1928,1935): Curso de Derecho político . Madrid.

ROSPIR ZABALA, J. I. (1981): Los orígenes de la opinión pública en España. Tesis Doctoral. Ciencias de la Información. Universidad Complutense. Madrid.

TIMOTÉo ALVAREZ, J. y otros (1989): Historia de los medios de comunicación en España. Ariel. Barcelona.

TUÑón DE LARA, M. (ed.) (1986): La prensa de los siglos XIX y XX. Universidad del País Vasco. Bilbao. 